\title{
Familial carpal tunnel syndrome with onset in childhood
}

\author{
G. DANTA \\ From the Staffordshire General Infirmary, Stafford
}

SYNOPSIS Within three generations of one family four patients were found to have the carpal tunnel syndrome. In father and son, symptoms commenced in the first decade, and in both patients the median nerves were found to be constricted under the transverse carpal ligaments. The only other operative finding was considerable thickening of the transverse carpal ligaments in the father. Thickening of the transverse carpal ligaments is unusual in patients with the carpal tunnel syndrome but is a common finding in the relatively few patients with familial carpal tunnel syndrome so far described in the literature. It is suggested that thickening of the ligaments may constitute a familial disorder that can give rise to the carpal tunnel syndrome in childhood or later in life.

The occurrence of the carpal tunnel syndrome in several generations of a family is uncommon, and the onset of symptoms in the first decade of life is unusual. The following is an account of four patients with this syndrome belonging to three generations of a family in two of whom symptoms began in childhood.

The family tree of the four patients described below is shown in Fig. 1. The sister of the propositus was examined clinically and found to be normal. Other family members were not examined; none of the patients knew of other relatives being similarly affected.

CASE L.H.

(SGI 308712; propositus) At the age of 2 years, this 8 year old boy complained of 'giddy' feelings in his fingers when he manipulated objects with his hands. A year or so later he complained of pain in the centre of his palm and numbness of the radial four fingers coming on after some 20 minutes of writing or drawing. When he transferred pen or crayon from the right to the left hand he developed similar symptoms in the latter. Resting his hands eased the pain and numbness, which then gradually disappeared in 10-15 minutes. Symptoms became more severe over the years, beginning after shorter periods of writing, and came to interfere significantly with his schoolwork. Symptoms had never wakened him at night,

(Accepted 26 November 1974.)

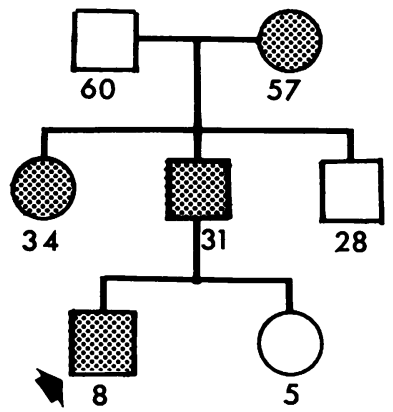

FIG. 1 Family tree of the four reported cases.

but at the age of 7 years he had pain in the hands first thing in the morning which disappeared when he shook them.

Sensation in the hands, including two-point discrimination, was normal. There was no muscle wasting, but he had slight weakness of both abductor pollicis brevis muscles. Tapping each median nerve at the wrist or elbow elicited pain in the palm. There were no other neurological signs and general physical examination was normal. Hydrocortisone $(12.5 \mathrm{mg})$ was injected into each carpal tunnel, relieving his symptoms for $4 \frac{1}{2}$ months. Thereafter injections were repeated with a similar result. During his school holidays both carpal tunnels were decompressed surgically. At operation both median nerves were constricted beneath the transverse carpal liga350 


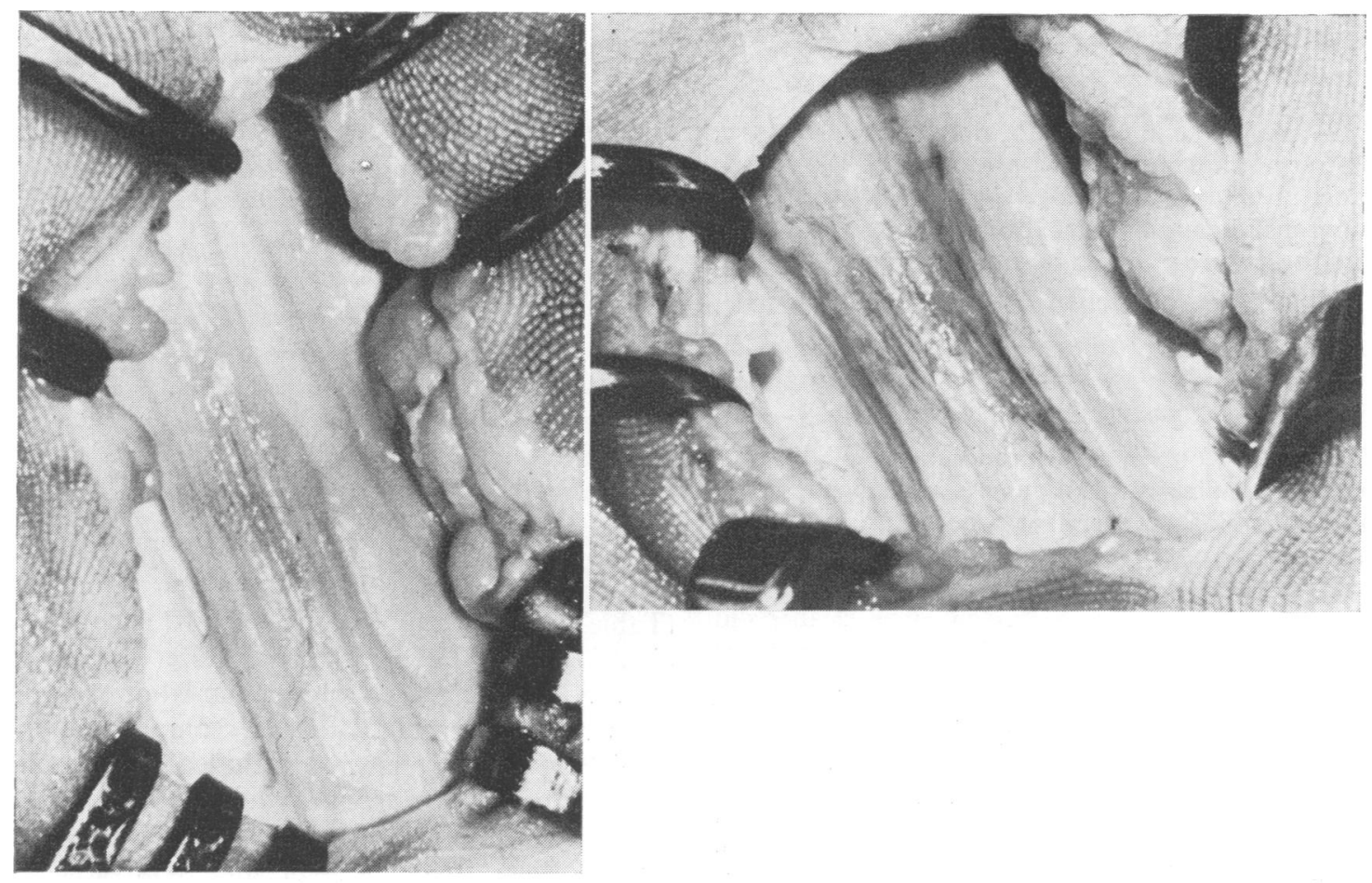

(a)

(b)

FIG. 2 Propositus: exposed median nerves in the carpal tunnel. (a) Slight constriction of left median nerve. (b) Moderate constriction with hyperaemia of right median nerve.

ments, the narrowing being greater on the right side (Fig. 2). The maximum thickness of the right transverse carpal ligament was $3 \mathrm{~mm}$, of the left $2.5 \mathrm{~mm}$. Histological examination of the ligaments and synovial membranes showed collagenous connective tissue without any evidence of amyloid or other specific pathological abnormality.

\section{CASE B.H.}

(SGI 195631) The 31 year old father of the propositus, a carpenter by trade, started to complain of nocturnal numbness and tingling in the hands at the age of 7 or 8 years. Shaking the hands relieved his symptoms. In his early 20 s symptoms worsened and he began to complain of pain in the palms, aching in the arms, and tingling and numbness in the fingers. These symptoms came on when he used his hands and also wakened him at night.

Sensation in the hands, including two-point discrimination, was quite normal. There was slight wasting and moderate weakness of both abductor pollicis brevis muscles, more so on the right side. There were no other neurological and no general medical signs.

At the age of 28 years both carpal tunnels were decompressed surgically, and this abolished his symptoms. At operation the median nerves were found constricted under considerably thickened transverse carpal ligaments.

\section{CASE C.H.}

This 34 year old paternal aunt of the propositus gave a 10 year history of pain and numbness of both hands in the mornings, which disappeared after she moved her hands about. Symptoms were infrequent, coming on perhaps two to four times a year. After knitting or painting she would develop stiffness of the hands which sometimes persisted for as long as a week. During her pregnancy at the age of 27 years symptoms in the hands were much more severe and she would wake at night with pain and tingling in the hands, which would subside when she moved her 
hands about. Symptoms were worse in the left hand.

There was no wasting of the thenar muscles, but she had slight weakness of the right, and moderate weakness of the left abductor pollicis brevis muscle. There was numbness to pin-prick over the tips of the radial three and a half fingers of the left hand. Twopoint discrimination over the finger tips was normal and there were no other abnormal signs on physical examination. Treatment was offered, but the patient declined it.

\section{CASE I.H.}

The 57 year old paternal grandmother of the propositus complained of numbness and tingling of all fingers coming on every few weeks during the past five years. Symptoms occurred only in the mornings and wore off after an hour or so. She did not knit, sew, or crochet and work as an office cleaner did not aggravate her symptoms. She had no symptoms in the hands during her three pregnancies.

There was moderate weakness but no wasting of the abductor pollicis brevis muscles. There was impaired pin-prick appreciation over the tips of the left index, middle, and radial half of the ring fingers, and of the right thumb, index, and middle fingers. Two-point discrimination was normal over the finger tips, and there were no other signs on physical examination. The patient did not wish to be treated.

INVESTIGATIONS The following tests were done on all patients and were found to be normal: radiographs of both wrists, thyroid function tests, sedimentation rate, and full blood count. The $\overrightarrow{2}$ results of nerve conduction studies are shown in Table 1.

\section{DISCUSSION}

While the clinical features of cases C.H. and I.H. are typical of the carpal tunnel syndrome, those of cases L.H. and B.H. are unusual in the very early age of onset of symptoms. Among published series of patients with the carpal tunnel syndrome there are only very few children (Table 2). The clinical features of 10 patientseight collected from the literature and two described in the present report-in whom symptoms started in childhood are summarized in Table 3. Cases were not included where the carpal tunnel syndrome was secondary to systemic disease or local abnormality at the wrist other than non-specific synovial of

TABLE 1

NERVE CONDUCTION STUDIES

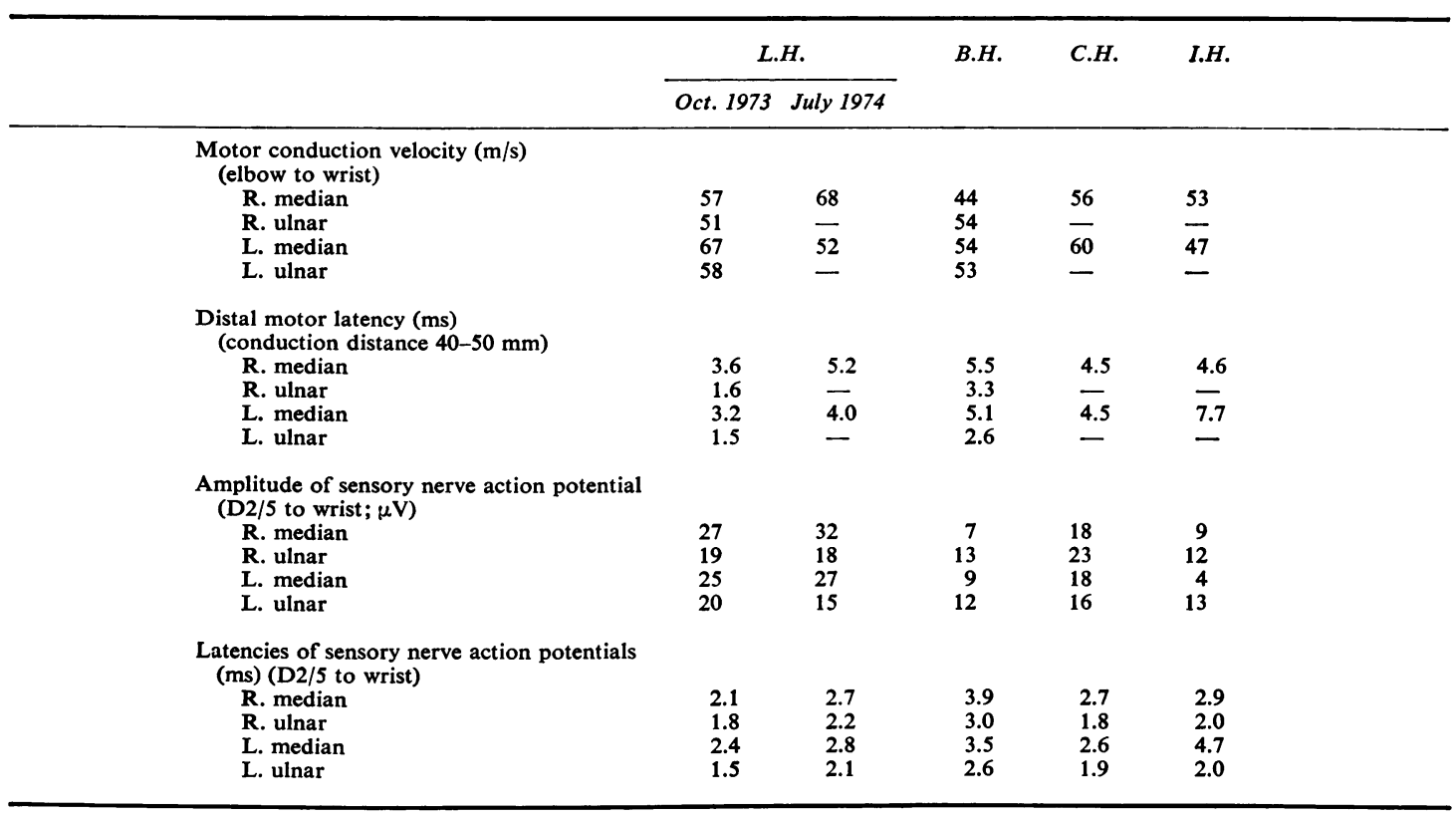


TABLE 2

AGE OF YOUNGEST PATIENT, FAMILIAL OCCURRENCE, AND DESCRIPTION OF TRANSVERSE CARPAL LIGAMENTS IN SEVERAL SERIES OF CARPAL TUNNEL SYNDROME

\begin{tabular}{|c|c|c|c|c|}
\hline Authors & No. & $\begin{array}{l}\text { Age of youngest } \\
\text { patient }(a)\end{array}$ & Family history & Transverse carpal ligament \\
\hline $\begin{array}{l}\text { Kremer et al. (1953) } \\
\text { Stephens and Welch (1956) }\end{array}$ & $\begin{array}{l}40 \\
16\end{array}$ & $\begin{array}{l}26 \\
23 \\
\text { (age at onset of } \\
\text { symptoms 13) }\end{array}$ & $\begin{array}{c}\text { NC } \\
1\end{array}$ & $\begin{array}{l}\text { NC } \\
\text { NC }\end{array}$ \\
\hline Heathfield (1957) & 80 & 21 & $\begin{array}{l}\text { 'There were no familial } \\
\text { cases in this series, } \\
\text { though they un- } \\
\text { doubtedly occur' }\end{array}$ & NC \\
\hline Garland et al. (1957) & 53 & 18 & NC & NC \\
\hline Phalen and Kendrick (1957) & 71 & 24 & 1 & NC \\
\hline Tanzer (1959) & 22 & NC & 4 & $\begin{array}{l}\text { No difference in thickness of transverse carpal } \\
\text { ligaments in patients with carpal tunnel } \\
\text { syndrome and in necropsy controls }\end{array}$ \\
\hline Crow (1960) & 81 & $>20$ & NC & $\begin{array}{l}\text { 'In one case the retinaculum was thought to be } \\
\text { abnormally dense' ( } 40 \text { operated wrists) }\end{array}$ \\
\hline Kendall (1960) & 327 & $>20$ & NC & $\begin{array}{l}\text { 'In ... those patients in whom trauma had } \\
\text { occurred in the palm of the hand in the } \\
\text { course of their occupations ...., marked } \\
\text { thickening of the transverse carpal ligament } \\
\text { was usually present, together with increased } \\
\text { flattening of the median nerve in the distal } \\
\text { part of the carpal tunnel' }\end{array}$ \\
\hline Mangini (1961) & 114 & NC & NC & $\begin{array}{l}\text { 'In all cases . . the transverse carpal ligament } \\
\text { was found to be normal and not responsible } \\
\text { for the compression' }\end{array}$ \\
\hline Kaeser (1963) & 130 & $\begin{array}{l}14 \\
\text { (patient with } \\
\text { gigantism) }\end{array}$ & NC & NC \\
\hline Nicolle and Woolhouse (1965) & 54 & 17 & NC & $\begin{array}{l}\text { In } 23 \text { cases there was 'tight thickened } \\
\text { retinaculum, synovitis without apparent } \\
\text { cause' }\end{array}$ \\
\hline Yamaguchi et al. (1965) & 1215 & 16 & NC & $\begin{array}{l}\text { 'No abnormality of the transverse carpal } \\
\text { ligament was found in any of these speci- } \\
\text { mens' }\end{array}$ \\
\hline Phalen (1966) & 439 & 20 & NC & $\begin{array}{l}\text { Variation in thickness of transverse carpal } \\
\text { ligament, but in no case was the transverse } \\
\text { carpal ligament compressing the nerve }\end{array}$ \\
\hline $\begin{array}{l}\text { Doyle and Carroll (1968) } \\
\text { Phalen (1972) }\end{array}$ & $\begin{array}{l}100 \\
384\end{array}$ & $\begin{array}{l}15 \\
21\end{array}$ & $\begin{array}{l}\text { NC } \\
\text { NC }\end{array}$ & $\begin{array}{l}\text { NC } \\
\text { NC }\end{array}$ \\
\hline
\end{tabular}

NC: no comment made.

ligamentous change. Among these 10 patients two pairs were related; there was no positive family history among the other six patients. Thickened transverse carpal ligaments were found at operation in the older member of each related pair of patients. No mention was made of thickened ligaments in any of the other patients.

The incidence of the carpal tunnel syndrome among family members of patients is not precisely defined in the literature. Few authors reporting on patients with the carpal tunnel syndrome refer to the familial occurrence of the disorder (Table 2). Since smaller rather than larger series contain patients with a positive family history, it is likely that in the latter the incidence of the carpal tunnel syndrome among family members was not adequately ascertained. Furthermore, the incidence of familial cases of the carpal tunnel syndrome may be higher than the literature suggests if it is remembered that the carpal tunnel syndrome was not widely recognized until after Brain et al. (1947) published the results of sectioning of the transverse carpal ligament in patients with the diagnosis of acroparaesthesiae. Patients described since that time may have had affected relatives in whom the diagnosis had not been made and a positive family history was therefore not obtained.

In addition to the two sisters reported by McArthur et al. (1959), two other families with the carpal tunnel syndrome have been reported. 
TABLE 3

CASES OF CARPAL TUNNEL SYNDROME PRESENTING IN CHILDHOOD

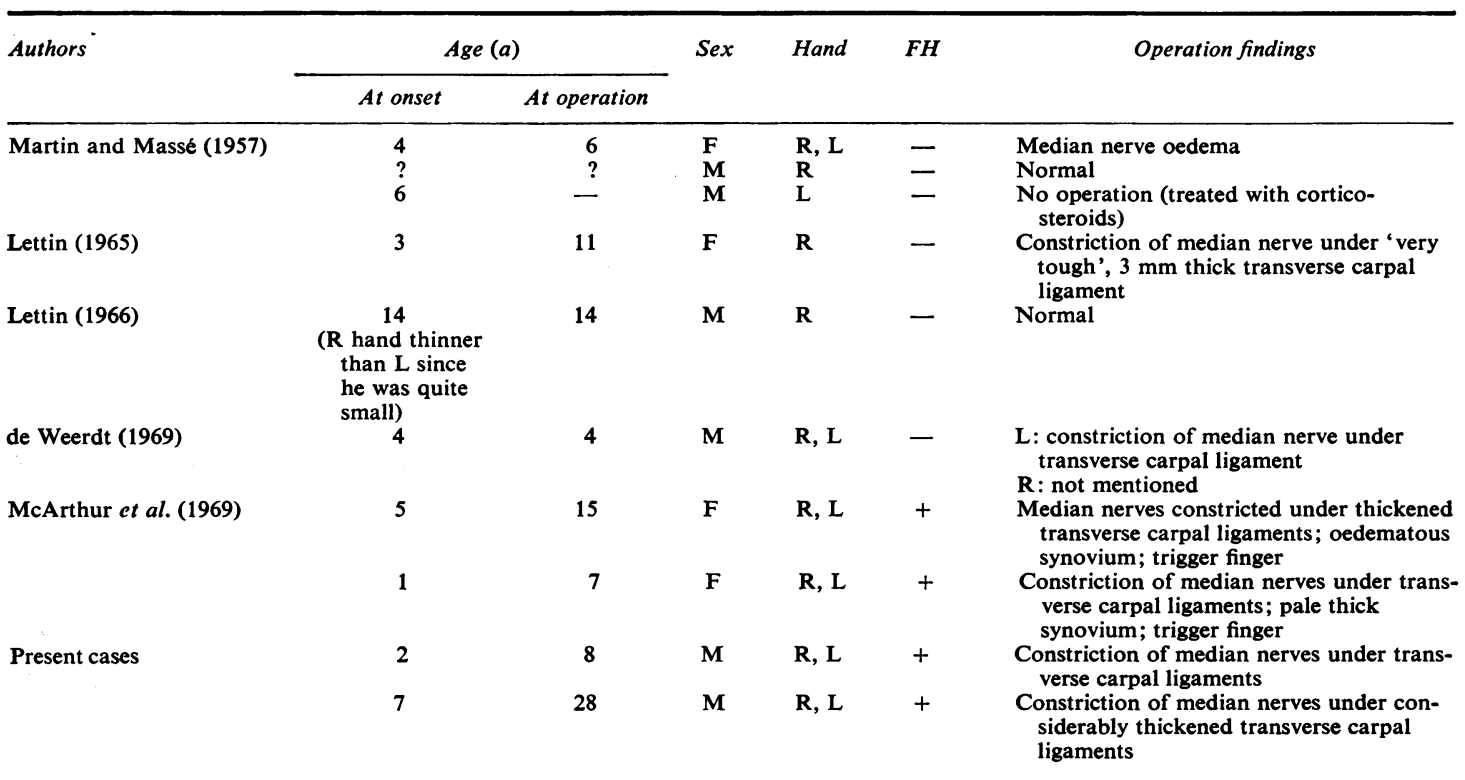

Zabriskie et al. (1935) described three sisters with thenar muscular atrophy and sensory symptoms in the fingers. Symptoms started at the age of 44,46 , and 49 years respectively, and the mother was said to have had a similar complaint. Although the authors attributed the disorder to hypertrophic arthritis of the cervical vertebrae, the clinical descriptions strongly suggest that the patients suffered from the carpal tunnel syndrome. Hess and Baumann (1969) reported on a family where three sisters aged 55 , 60 , and 63 years and the daughter of one of them aged 30 years had the carpal tunnel syndrome. The sisters' symptoms started with the menopause and the daughter's with pregnancy. At operation the median nerves were found to be constricted under massively thickened transverse carpal ligaments which were sclerosed and discoloured yellow.

Thickening of the transverse carpal ligament is a common finding among familial patients with the carpal tunnel syndrome. This was found in all four patients reported by Hess and Baumann (1969), in the elder sister reported by McArthur et al. (1969) who had the operation at the age of 15 years, and in the father of the propositus of the present report who had his operation at the age of 28 years. It is interesting that the younger members of the last two families who were both operated on at the age of seven years did not have thickened transverse carpal ligaments.

Thickening of the transverse carpal ligaments has not been a feature of the other patients whose symptoms started in childhood, nor of patients included in published series (Table 2). Tanzer (1959) found that the thickness of the transverse carpal ligaments in 11 operated wrists of patients with the carpal tunnel syndrome was no different from that in 11 necropsy controls. Although it is unlikely that the transverse carpal ligament is responsible for median nerve compression in the majority of patients with the carpal tunnel syndrome other than by containing the nerve within the carpal tunnel, thickening of the ligament may be expected to reduce the size of the carpal tunnel and could, without the contribution of other factors, result in compression of the median nerve. This mechanism seems to be responsible for the carpal tunnel syndrome 
in patients with pleonosteosis (Watson-Jones, 1949), and thickening of the transverse carpal ligament in acromegaly may contribute to median nerve compression in that disorder (Johnston, 1960). In amyloidosis thickening of the tendon sheaths rather than the transverse carpal ligaments may result in compression of the median nerves in the carpal tunnel (Grokoest and Demartini, 1954). However, Lambird and Hartmann (1969) argue from pathological evidence that in their patients with familial amyloidosis and carpal tunnel syndrome the transverse carpal ligaments, which were infiltrated with amyloid material, though not thickened, were directly responsible for compression of the median nerves. Since their patients also had an amyloid neuropathy it is possible that slight and not grossly obvious thickening of the ligaments produced a compression neuropathy in already abnormal nerves. Amyloidosis is a cause of familial carpal tunnel syndrome, but there was no evidence of amyloid disease in any of the patients in this report nor was any amyloid material seen in the transverse carpal ligaments or synovial tissue of the propositus.

Non-specific thickening of the transverse carpal ligaments thus seems to be a feature of familial cases of the carpal tunnel syndrome. Although the number of familial patients so far studied is small, it is tempting to think that thickening of the transverse carpal ligaments may be a familial disorder which can give rise to compression of the median nerve in the carpal tunnel. Patients may present in early childhood, but visible thickening of the transverse carpal ligaments may not become evident until later years.

\section{REFERENCES}

Brain, W. R., Wright, A. D., and Wilkinson, M. (1947). Spontaneous compression of both median nerves in the carpal tunnel. Six cases treated surgically. Lancet, 1, 277282.

Crow, R. S. (1960). Treatment of the carpal-tunnel syndrome. British Medical Journal, 1, 1611-1615.

Doyle, J. R., and Carroll, R. E. (1968). The carpal tunnel syndrome. A review of 100 patients treated surgically. California Medicine, 108, 263-267.

Garland, H., Bradshaw, J. P. P., and Clark, J. M. P. (1957). Compression of median nerve in carpal tunnel and its relation to acroparaesthesiae. British Medical Journal, 1, 730-734.
Grokoest, A. W., and Demartini, F. E. (1954). Systemic disease and the carpal tunnel syndrome. Journal of the American Medical Association, 155, 635-637.

Heathfield, K. W. G. (1957). Acroparaesthesiae and the carpal-tunnel syndrome. Lancet, 2, 663-666.

Hess, H., and Baumann, F. (1969). Über das familiäre Vorkommen eines beidseitigen Karpaltunnelsyndroms. Zeitschrift für Orthopädie und ihre Grenzgebiete, 106, 565569.

Johnston, A. W. (1960). Acroparaesthesiae and acromegaly. British Medical Journal, 1, 1616-1618.

Kaeser, H. E. (1963). Diagnostische Probleme beim Karpaltunnelsyndrom. Deutsche Zeitschrift für Nervenheilkunde, 185, 453-470.

Kendall, D. (1960). Aetiology, diagnosis, and treatment of paraesthesiae in the hands. British Medical Journal, 2, 1633-1640.

Kremer, M., Gilliatt, R. W., Golding, J. S. R., and Wilson, T. G. (1953). Acroparaesthesiae in the carpal-tunnel syndrome. Lancet, 2, 590-595.

Lambird, P. A., and Hartmann, W. H. (1969). Hereditary amyloidosis, the flexor retinaculum, and the carpal tunnel syndrome. American Journal of Clinical Pathology, 52, 714719.

Lettin, A. W. F. (1965). Carpal tunnel syndrome in childhood. Report of a case. Journal of Bone and Joint Surgery, 47B, $556-559$.

Lettin, A. W. F. (1966). Carpal tunnel syndrome in childhood. Proceedings of the Royal Society of Medicine, 59, 705.

McArthur, R. G., Hayles, A. B., Gomez, M. R., and Bianco, A. J., Jr (1969). Carpal tunnel syndrome and trigger finger in childhood. American Journal of Diseases of Children, 117, 463-469.

Mangini, U. (1961). Some remarks on the etiology of the carpal tunnel compression of the median nerve. Bulletin of the Hospital for Joint Diseases, 22, 56-64.

Martin, C., and Massé, P. (1958). Le syndrome du canal carpien chez l'enfant. Archives Françaises de Pédiatrie, 15, 930-940.

Nicolle, F. V., and Woolhouse, F. M. (1965). Nerve compression syndromes of the upper limb. Journal of Trauma, 5 , 313-318.

Phalen, G. S. (1966). The carpal-tunnel syndrome. Journal of Bone and Joint Surgery, 48A, 211-228.

Phalen, G. S. (1972). The carpal-tunnel syndrome. Clinical evaluation of 598 hands. Clinical Orthopaedics and Related Research, 83, 29-40.

Phalen, G. S., and Kendrick, J. I. (1957). Compression neuropathy of the median nerve in the carpal tunnel. Journal of the American Medical Association, 164, 524-530.

Stephens, J., and Welch, K. (1956). Acroparesthesia. A symptom of median nerve compression at the wrist. Archives of Surgery, 73, 849-854.

Tanzer, R. C. (1959). The carpal-tunnel syndrome. A clinical and anatomical study. Journal of Bone and Joint Surgery, 41A, 626-634.

Watson-Jones, R. (1949). Léri's pleonosteosis, carpal tunnel compression of the median nerves and Morton's metatarsalgia. Journal of Bone and Joint Surgery, 31 B, 560-571.

Weerdt, C. J. de (1969). Het carpale-tunnelsyndroom bij een vierjarige jongen. Nederlandsch Tijdschrift voor Geneeskunde, 113, 1942-1943.

Yamaguchi, D. M., Lipscomb, P. R., and Soule, E. H. (1965). Carpal tunnel syndrome. Minnesota Medicine, 48, 22-33.

Zabriskie, E. G., Hare, C. C., and Masselink, R. J. (1935). Hypertrophic arthritis of cervical vertebrae with thenar muscular atrophy occurring in three sisters. Bulletin of the Neurological Institute of New York, 4, 207-220. 